\title{
Maternal HIV infection and preeclampsia increased risk of low birth weight among newborns delivered at University of Gondar specialized referral hospital, Northwest Ethiopia, 2017
}

\author{
Daniale Tekelia Ekubagewargies ${ }^{1 *}$ (iD, Destaye Guadie Kassie ${ }^{1}$ and Wubet Worku Takele ${ }^{2}$
}

\begin{abstract}
Introduction: Globally, more than 20 million infants are born with low birth weight. The risk of neonatal mortality among low birth weight infants is 25 to 30 times greater than neonates with birth weight $\geq 2500 \mathrm{~g}$. Low birth weight infants are at increased risk of infection, difficulty of feeding, and neurologic problems following birth. So far, the prevalence and factors associated with low birth weight have not been studied in the study area after completion of the time set for millennium development goals. Therefore, the study was aimed at assessing the prevalence and associated factors of low birth weight among newborns delivered at University of Gondar specialized referral hospital, Northwest Ethiopia, 2017.

Methods: Institution-based retrospective cross-sectional study was conducted from April 1 to May 28, 2017. A total of 240 newborns were included in the study. Systematic random sampling technique was used for selecting study participant's medical record charts from delivery registration log book. Data were collected using data extraction tool. Binary logistic regression followed by multivariable regression model was fitted and interpretation was made based on the adjusted odds ratio and $p$-value of less than 0.05 with corresponding $95 \% \mathrm{Cl}$.

Results: The prevalence of low birth weight was $12.9 \%$ (95\%Cl: 8.94, 17.83\%). No history of preeclampsia (AOR $=0.193$, 95\%Cl: 0.0516, 0.723), negative maternal HIV infection ( $\mathrm{AOR}=0.015,95 \% \mathrm{Cl}: 0.001,0.277)$, and being preterm (AOR $=17$. $6,95 \% \mathrm{Cl}: 5.18,60.17)$ were significantly associated with low birth weight.

Conclusion and recommendations: The result of this study highlighted that the burden of low birth weight is a public health concern among babies delivered in University of Gondar specialized referral Hospital. Maternal HIV infection, preeclampsia, and prematurity were associated with low birth weight. Prevention and treatment of Human immunodeficiency virus infection during pregnancy, tackling prematurity and prevention of preeclampsia through strengthening of antenatal care service and other comprehensive strategies are strongly recommended.
\end{abstract}

Keywords: Gondar, Ethiopia, Low birth weight, Newborns

\footnotetext{
* Correspondence: dtekle16@gmail.com

${ }^{1}$ Department of Pediatrics and Child Health Nursing, School of Nursing,

College of Medicine and Health Sciences, University of Gondar, Gondar,

Ethiopia

Full list of author information is available at the end of the article
}

(c) The Author(s). 2019 Open Access This article is distributed under the terms of the Creative Commons Attribution 4.0 International License (http://creativecommons.org/licenses/by/4.0/), which permits unrestricted use, distribution, and reproduction in any medium, provided you give appropriate credit to the original author(s) and the source, provide a link to the Creative Commons license, and indicate if changes were made. The Creative Commons Public Domain Dedication waiver (http://creativecommons.org/publicdomain/zero/1.0/) applies to the data made available in this article, unless otherwise stated. 


\section{Background}

According to the World Health Organization (WHO), low birth weight (LBW) is defined as weight at birth less than $2500 \mathrm{~g}$ [1]. Its severity is categorized as low birth weight $(<2500 \mathrm{~g})$, very low birth weight $(<1500 \mathrm{~g})$, and extremely low birth weight $(<1000 \mathrm{~g})$ [2] [3]. It is one of the major determinants of perinatal survival, developmental disabilities, and illnesses later in life [4]. Globally, it is estimated between 15 and $20 \%$ of all births, which is more than 20 million births per year, is LBW [1]. South-central Asia (27\%) and sub-Saharan Africa (15\%) share the majority of the burden [3]. According to the 2016 Ethiopian Demographic and Health Survey (EDHS) report, about 13\% of newborns are LBW [5]. LBW is a significant risk factor for adverse health outcomes including, but are not limited to, respiratory distress syndrome, intracranial hemorrhage, patent ductus arteriosus, necrotizing enterocolitis, and retinopathy of prematurity [6] [7] [8]. Moreover, risk of obesity, metabolic syndrome, neurological impairments, and cardiovascular disease in the later age are observed among LBW babies [9], [10].

It is estimated that LBW contributes to 60 to $80 \%$ of all neonatal mortality [6]. A study on the economic burden of LBW showed that it results in lower full-time earning, reduced educational competency, and higher body mass index later in life [11]. LBW newborns stay in hospital on average for 12.9 days after birth, which is far higher as compared to healthy newborns who spend less than 2 days [12]. This is even longer for very low birth weight infants for whom the average hospital stay is 57.5 days [13]. Besides, the average hospital service cost for these babies is $75 \%$ higher than babies weighing $1000-1499 \mathrm{~g}$ at birth [14].

Studies show that factors contributing to LBW are multifactorial. The following factors have increased the likelihood of being LBW in the newborn; young maternal age, primiparity, lower education level, and poor maternal nutritional status both preconception and during pregnancy [7], [15]. As a matter of fact, empirical studies from different countries show that birth weight outcome is associated with maternal anthropometric measurements [16], [17].

Ethiopia has achieved the fourth Millennium Development Goal (MDG) of the United Nations which targeted to reduce child mortality by two-thirds from 1990 to 2015 [18] [19]. However, there is a scarce of site-specific literature on the magnitude of LBW that shows the progress post-2015 MDG declaration.

Therefore, the aim of this study was to determine the prevalence and factors associated with LBW among newborns delivered at University of Gondar specialized referral hospital. This gives an insight into a useful child health indicator and could help in better evidence-based interventions in Ethiopia aimed at further reducing neonatal mortality.

\section{Methods}

\section{Study design and setting}

A cross-sectional study design was conducted from April 1 to May 28, 2017, at the University of Gondar comprehensive specialized referral Hospital, northwest Ethiopia. The hospital is providing service for more than 7 million people of Gondar town and the catchment area. The maternity division of the hospital is composed of antenatal care (ANC) clinic, postnatal clinic, and two delivery wards. It's staffed with intern doctors, 37 midwives, 26 obstetricians, and 24 supportive staff. In 2016, a total of 7590 births were attended at the hospital.

\section{Study participants and eligibility criteria}

All weighted live births with complete records delivered at the University of Gondar comprehensive specialized referral Hospital were included.

\section{Sample size, sampling technique, and sampling procedures}

To estimate the sample size, single population proportion formula was used by considering the following statistical assumptions; prevalence of LBW, $17.1 \%$ [8], 95\% confidence interval (CI), 5\% margin of error, and $10 \%$ non-response rate to yield a total of 240 study participants. Systematic random sampling technique was employed to select study participant's medical records. The delivery registration logbook was used as sampling frame. To determine the interval, the number of all births during the study period (648) was divided by the sample size (240) to give 2. To select the first participant among the two, lottery method was used. Accordingly, the second medical record was the starting point to select and every other medical record were included. Whenever the selected chart did not fulfill the criteria (incompleteness), the next medical record was considered.

\section{Data collection procedure and tools}

The patients' medical records and physician order sheet were used as source of data. The data, consisting of socio-demographic variables, clinical and obstetric history as well as birth outcome, were collected using data extraction tool. Four registered nurses collected the data, while two other supervised the data collection process. Data quality was maintained by the following data quality control mechanisms; the data extraction tool was pretested on $5 \%$ of the sample (i.e. 12 charts) at Felegehiwot referral hospital. One day training was given to data collectors and supervisors. Strict supervision of the data collection was carried out throughout the data collection period. The collected data was checked for its consistency and completeness before any attempt to enter, code and analyze it. 


\section{Data processing and analysis}

The collected data was coded, entered into Epi-Info version 7, and exported to SPSS version 20 software for analysis. The results were presented using frequency, tables, text, and graphs. Variables with a $p$-value of $\leq 0.2$ in the bi-variable analysis were exported to the multivariable model to control the possible effects of confounders, as well as to identify statistically significant variables. Adjusted odds ratio (AOR) with corresponding 95\% confidence interval was computed and variables having $p$-value of less than 0.05 in the multivariable model were considered significantly associated with LBW.

\section{Results}

\section{Socio-demographic characteristics of participants}

A total of 240 participants were enrolled in the study. The mean $(+\mathrm{SD})$ age of the mothers was $27.1( \pm 5.3)$ Years. About $59.3 \%$ were urban residents and the vast majority (97.8\%) of them were married. Moreover, $60.8 \%$ of the mothers were unemployed (Table 1).

\section{Medical and obstetric characteristics}

One hundred and five (43.5\%) of the mothers were primiparous. Almost all (99.8\%) of the mothers had 1st ANC follow up. One hundred forty eight (61.9\%) had at

Table 1 Socio-demographic characteristics of study participants at University of Gondar specialized referral hospital, northwest Ethiopia, $2017(n=240)$

\begin{tabular}{lll}
\hline Characteristic & Frequency $(\mathrm{n})$ & Percent $(\%)$ \\
\hline Maternal age & 10 & 4.2 \\
$15-19$ & 68 & 28.3 \\
$20-24$ & 90 & 37.5 \\
$25-29$ & 35 & 14.6 \\
$30-34$ & 37 & 15.5 \\
$35-39$ & & \\
$40-44$ & & \\
Residence & 143 & 59.6 \\
Urban & 97 & 40.4 \\
Rural & & \\
Marital status & 233 & 97.1 \\
Married & 7 & 2.9 \\
Divorced & & \\
Occupation & 146 & 60.8 \\
Unemployed & 67 & 27.9 \\
Governmental & 27 & 11.3 \\
Nongovernmental & 217 & 90.4 \\
Religion & 23 & \\
Orthodox Christian & & \\
Muslim & & \\
\hline
\end{tabular}

least four ANC visits during current pregnancy. Dominant number of participants (72.5\%) were registered for ANC follow-up in the second trimester. In this study, the majority $(86.7 \%)$ of pregnant women were supplemented with Iron/Folic acid during the ANC follow up. About one in 10 (10.2\%) of participants had history of abortion. Regarding HIV/AIDS infection, the vast majority $(97.9 \%)$ of the mothers were non-reactive. Majority (85.8\%) of women gave birth between 37and 42 weeks of pregnancy. A bit greater than half $(54.6 \%)$ of newborns were males. Regarding the mode of delivery, $75 \%$ were spontaneous vaginal delivery (SVD) (Table 2).

\section{Prevalence of low birth weight (LBW)}

The prevalence of LBW was 12.9\% (95\% CI: 8.94, $17.83 \%)$. The mean birth weights of newborns was $2882.5 \pm 471.3 \mathrm{~g}$. Out of male births, 18 (13.7\%) were LBW, while 13 (11.93\%) female newborns were LBW.

\section{Factors associated with LBW}

In the bi-variable analysis, history of preeclampsia, hemoglobin level, number of ANC visits, gestational age, maternal HIV infection, place of residence, and iron supplementation were statistically significant at a $p$-value of 0.2 . However, in the multivariable model, only gestational age, history of preeclampsia, and maternal HIV infection were significantly associated with LBW.

Accordingly, the likelihood of giving LBW baby among mothers with no history of preeclampsia in the current pregnancy decreased by $81 \% \quad(\mathrm{AOR}=0.193$; [95\%CI: $0.0516,0.723]$ as compared to their counterparts. The odds of being LBW for babies who were delivered from HIV uninfected mothers was reduced by $98.5 \%$ (AOR = $0.015,95 \% \mathrm{CI}: 0.001,0.277)$ as compared to their counterparts. Moreover, mothers who gave birth prematurely (before 37 weeks) were 17.6 times more likely to deliver LBW babies as compared to mothers who gave birth after 37-weeks of gestation $(\mathrm{AOR}=17.6,95 \% \mathrm{CI}$ : $5.18,60.17)$. (Table 3).

\section{Discussion}

Globally, birth weight has been accepted as the single most important determinant of future chances of infant survival, healthy growth and freedom from morbidities and mortalities [4]. The prevalence of low birth weight in this study was $12.9 \%$ (95\% CI: CI: 8.94, 17.83\%). This result suggests that $\mathrm{LBW}$ still continues to be a public health problem in the study area. Therefore, a comprehensive strategy has to be designed to combat the problem.

The result of this study is in line with the EDHS report (13\%) [6], and other studies conducted in Gondar (11.2\%) [20], (Axum 9.9\%) [21], and Kenya 12.3\% [2]. 
Table 2 Medical and Obstetric Characteristics of study participants at Gondar University specialized hospital, 2017. $(n=240)$

\begin{tabular}{cc}
\hline Characteristic & F \\
\hline Parity & 1 \\
1 & 62 \\
2 & 3 \\
3 & 10 \\
4 & 14 \\
5 & 9 \\
6 & \\
Gravidity & \\
1 & 98 \\
2 & 32 \\
3 & 38 \\
4 & 14 \\
5 & 12 \\
6 & 7 \\
7 & 7 \\
8 & 2 \\
History of abortion &
\end{tabular}

Yes 25

No 215

Mother Blood group

A+

A-

$\mathrm{B}+$

B-

$A B$

$\mathrm{O}+$

O-

Gestational age by week

$$
\begin{aligned}
& <37 \text { weeks } \\
& 37-42 \text { weeks } \\
& >42 \text { weeks }
\end{aligned}
$$

Had ANC follows up

Yes

No

HIV status of the mother

Negative

Positive

Iron supplement of the mother

$$
\text { Yes }
$$$$
\text { No }
$$

Malaria during pregnancy

No

Frequency Percent

105

36

10

\begin{tabular}{|c|c|c|}
\hline Characteristic & Frequency & Percent \\
\hline \multicolumn{3}{|l|}{ TB infection during pregnancy } \\
\hline Yes & 1 & .4 \\
\hline No & 239 & 99.6 \\
\hline \multicolumn{3}{|c|}{ Had preeclampsia during pregnancy } \\
\hline Yes & 31 & 12.9 \\
\hline No & 209 & 87.1 \\
\hline \multicolumn{3}{|c|}{ Had vaginal bleeding during pregnancy } \\
\hline Yes & 7 & 2.9 \\
\hline No & 233 & 97.1 \\
\hline \multicolumn{3}{|l|}{ Had PROM during pregnancy } \\
\hline Yes & 32 & 13.3 \\
\hline No & 208 & 86.7 \\
\hline \multicolumn{3}{|l|}{ Mode of delivery } \\
\hline Spontaneous vaginal delivery & 180 & 75.0 \\
\hline Assisted vaginal delivery & 15 & 6.3 \\
\hline Caesarian section & 45 & 18.8 \\
\hline \multicolumn{3}{|l|}{ Type of delivery } \\
\hline \multicolumn{3}{|l|}{ Number of ANC follow-up } \\
\hline One visit & 12 & 5.0 \\
\hline Two visits & 37 & 15.4 \\
\hline Three visits & 42 & 17.5 \\
\hline Four or more visits & 148 & 61.1 \\
\hline \multicolumn{3}{|l|}{ Hemoglobin Level of mother } \\
\hline Anemic (<12 mg/dl) & 40 & 16.7 \\
\hline Not Anemic (> $12 \mathrm{~g} / \mathrm{dl})$ & 200 & 83.3 \\
\hline
\end{tabular}

Table 2 Medical and Obstetric Characteristics of study participants at Gondar University specialized hospital, 2017. $(n=240)$ (Continued)

$\mathrm{PROM}=$ Premature Rupture Of Membrane

On the other hand, this study found lower prevalence of LBW as compared to studies conducted in Jimma Zone, Ethiopia (22.5\%) [22], Kersa, Ethiopia, (28.3\%) [23], and India (20\%) [24].The possible reason for this discrepancy might be the time difference in which the studies were conducted. There is almost a decade time gap between the current study and the one conducted in Jimma and Kersa. Advancements in health care coverage as well as quality of care over time could lead to decrement in adverse birth outcomes including LBW. For example, according to the 2016 EDHS report [5], the coverage of ANC service utilization, one indicator of maternal health care delivery, has been improved. With regard to the Indian study, it was community-based study, while the current study is institution-based, more specifically, health institution. Mothers who give birth at health institutions are presumed to receive better ANC follow-up with appropriate interventions that significantly reduces adverse 
Table 3 Bivariate and multivariate logistic regression analysis of low birth weight at University of Gondar specialized hospital, 2017.

\begin{tabular}{|c|c|c|c|c|}
\hline \multirow[t]{2}{*}{ Characteristics } & \multicolumn{2}{|c|}{ Low birth weight } & \multirow[t]{2}{*}{ Crude OR } & \multirow[t]{2}{*}{ Adjusted OR } \\
\hline & No & Yes & & \\
\hline \multicolumn{5}{|c|}{ ANC follow-up visits } \\
\hline First & 7 & 5 & 1 & 1 \\
\hline Second & 26 & 11 & $0.59(0.15,2.27)$ & $0.67(0.11,4.2)$ \\
\hline Third & 37 & 5 & $0.19(0.043,0.83)$ & $0.29(0.039,2.15)$ \\
\hline Fourth & 139 & 9 & $0.09(0.024,0.34)$ & $0.16(0.22,1.12)$ \\
\hline \multicolumn{5}{|l|}{ Preeclampsia } \\
\hline Yes & 23 & 8 & 1 & 1 \\
\hline No & 186 & 23 & $0.35(0.14,0.87)$ & $0.19(0.052,0.722)^{*}$ \\
\hline \multicolumn{5}{|c|}{ Hemoglobin level } \\
\hline$<12 \mathrm{mg} / \mathrm{dl}$ & 27 & 13 & 1 & 1 \\
\hline$>12 \mathrm{mg} / \mathrm{dl}$ & 182 & 19 & $0.22(0.102,0.53)$ & $0.30(0.09,1.002)$ \\
\hline \multicolumn{5}{|l|}{ Gestational age } \\
\hline$<37$ weeks & 9 & 15 & $20.83(7.89,54.9)$ & $17.66(5.18,60.16)^{*}$ \\
\hline$>37$ weeks & 200 & 16 & 1 & 1 \\
\hline \multicolumn{5}{|c|}{ Maternal HIV infection } \\
\hline Reactive & 2 & 3 & 1 & 1 \\
\hline Non-reactive & 207 & 28 & $0.09(0.014,0.56)$ & $0.015(0.009,0.28)^{*}$ \\
\hline \multicolumn{5}{|c|}{ Place of residence } \\
\hline Urban & 130 & 13 & 1 & 1 \\
\hline Rural & 79 & 18 & $2.27(1.05,4.90)$ & $1.39(0.40,4.82)$ \\
\hline \multicolumn{5}{|c|}{ Iron supplementation } \\
\hline Yes & 189 & 20 & 1 & 1 \\
\hline No & 19 & 12 & $5.96(2.53,14.06)$ & $1.59(0.43,5.88)$ \\
\hline
\end{tabular}

*Significant association at a $p$-value of 0.05

birth outcomes including LBW [8], [23], [25]. There is also half a decade time difference between the current and Indian study.

The result of this study is higher than studies conducted at Laelay Maichew district, Ethiopia (6.3\%) [21], Wolaita Sodo, Ethiopia (8.1\%) [26], and Yazd, Iran (8.8\%) [27]. Differences in living conditions and maternal characteristics may have been reasons for discrepancy as the current study was conducted in urban setting, while the study conducted in Lalay Maichew was in rural setting. The difference in LBW prevalence between the current study and Wolaita Sodo could be due to the fact that the later only considered term deliveries which in fact reduces the prevalence of LBW. The possible reasons for the difference between the current study and a study conducted in Iran could be the difference in socio-demographic characteristics, health service delivery and the way of treating mothers during follow-up care.

The likelihood of giving LBW baby among mothers with no history of preeclampsia in the current pregnancy was decreased by $81 \%$ compared to their counterparts. This study is supported by studies conducted in Norway [28], Tanzania [29], and Canada [30]. The possible reason might be due to the reduced placental blood flow that results in decreased fetal growth, with an increased risk of intrauterine growth restriction and low birth weight [31].

The odds of giving birth to LBW baby among mothers who were HIV uninfected was reduced by $98.5 \%$ as compared to those mothers who were HIV infected. The finding of this study is in line with a study conducted in Gondar University Hospital [8], Tanzania [29], and a systematic review and meta-analysis study conducted in developing, as well as developed countries [32]. Maternal weight loss secondary to low dietary intake (loss of appetite, mouth ulcers, food insecurity), malabsorption, and altered metabolism is common in HIV infected people [33]. This further causes LBW in newborns as weight is a key maternal anthropometric characteristic that defines birth weight [17]. In utero, HIV infection could also be a risk factor for LBW [34]. In addition, mothers 
who are on anti-retroviral drugs, especially protease inhibitors are at risk of preterm labor [35], which might in turn cause LBW.

Moreover, this study revealed a positive association between preterm birth and LBW. The likelihood of being LBW baby is increased among premature babies. This is in agreement with studies carried out in Jimma, Ethiopia [22], Gondar, Ethiopia [8], Debrebirhan, Ethiopia [37], Kenya [2], Tanzania [29], and India [36]. This could be due to the fact that preterm birth happens before completion of intrauterine growth, a time when the desired birth weight has not been gained, which leads to LBW [4], [38].

\section{Conclusion}

In summary, this study demonstrated that LBW is a public health problem among babies delivered at the University of Gondar specialized referral Hospital. Absence of maternal HIV infection, preeclampsia, and preterm delivery were factors that positively predicted LBW. Prevention and treatment of HIV infection, prevention of preeclampsia by strengthening ANC services, and preventing prematurity are highly recommended.

\section{Abbreviations}

ANC: Antenatal Care; EDHS: Ethiopian Demographic and Health Survey; HIV: Human Immune Virus; IQR: Inter Quartile Range; LBW: Low Birth Weight; MDG: Millennium Development Goals; WHO: World Health Organization

\section{Acknowledgments}

Our gratitude goes to the University of Gondar College of medicine and health science school of Nursing for the approval of the ethical clearance. The authors would like to thank data collectors and supervisors for their commitment and the hospital administration for their unreserved collaboration.

\section{Funding}

Authors of this study did not receive any funding for the project.

\section{Availability of data or materials}

All necessary data generated, or analyzed during this study are included in this manuscript.

\section{Authors' contributions}

DTE wrote the proposal, supervised the data collection process, analyzed the data and drafted the manuscript. DGK approved the proposal with revisions, participated in data analysis and revised subsequent drafts of the manuscript. WWT approved the proposal with revisions, participated in data analyses and revised subsequent drafts of the manuscript. All authors read and approved the final manuscript.

\section{Authors' information}

DTE: Lecturer in the Department of Pediatrics and Child Health Nursing School of Nursing, College of Medicine and Health Science, University of Gondar, Ethiopia.

DGK: Lecturer in the Department of Pediatrics and Child Health Nursing, School of Nursing, College of Medicine and Health Science, University of Gondar, Ethiopia.

WWT: Lecturer in the Department of community health Nursing, School of Nursing, College of Medicine and Health Sciences, University of Gondar, Ethiopia

\section{Ethics approval and consent to participate}

Ethical approval was obtained from University of Gondar, College of Medicine and Health Sciences, School of Nursing Ethical Review Committee, in a letter with a reference number: N/S/5512/06/09. Letter of permission for data collection was obtained from the hospital medical director's office. The confidentiality of patient-related data was maintained by avoiding possible identifiers, such as the name of the mother; only numerical identification was used as a reference. After the whole data collection, the data extraction tool was locked and kept confident throughout the whole process of the research work.

\section{Consent for publication}

Not applicable.

\section{Competing interests}

The authors of this study declare that they have no any competing interest.

\section{Publisher's Note}

Springer Nature remains neutral with regard to jurisdictional claims in published maps and institutional affiliations.

\section{Author details}

${ }^{1}$ Department of Pediatrics and Child Health Nursing, School of Nursing, College of Medicine and Health Sciences, University of Gondar, Gondar, Ethiopia. ${ }^{2}$ Department of Community Health Nursing, School of Nursing, College of Medicine and Health Sciences, University of Gondar, Gondar, Ethiopia.

Received: 1 August 2018 Accepted: 3 January 2019

Published online: 10 January 2019

\section{References}

1. WHO | Global Nutrition Targets 2025: Low birth weight policy brief [internet]. WHO. [cited 2018 Jul 6]. Available from: http://www.who.int/ nutrition/publications/globaltargets2025 policybrief_lbw/en/

2. Muchemi OM, Echoka E, Makokha A. Factors associated with low birth weight among neonates born at Olkalou District Hospital, Central Region, Kenya. Pan Afr Med J [Internet]. 2015 Jan 1 [cited 2018 Jul 11];20(1). Available from: https://www.ajol.info/index.php/pamj/article/view/114373

3. Battaglia FC, Lubchenco LO. A practical classification of newborn infants by weight and gestational age. J Pediatr. 1967 Aug 1;71(2):159-63.

4. Lira PIC, Ashworth A, Morris SS. Low birth weight and morbidity from diarrhea and respiratory infection in Northeast Brazil. J Pediatr. 1996 Apr 1; 128(4):497-504

5. CSA/Ethiopia CSA-, ICF. Ethiopia Demographic and Health Sruvey 2016. 2017 [cited 2018 Jul 6]; Available from: http://dhsprogram.com/publications/ publication-fr328-dhs-final-reports.cfm

6. Wardlaw TM. Low Birthweight: Country, Regional and Global Estimates. UNICEF; 2004. 31 p.

7. Guyatt HL, Snow RW. Impact of malaria during pregnancy on Low birth weight in sub-Saharan Africa. Clin Microbiol Rev. 2004 Oct 1;17(4):760-9.

8. Zeleke BM, Zelalem M, Mohammed N. Incidence and correlates of low birth weight at a referral hospital in Northwest Ethiopia. Pan Afr Med J [Internet]. 2012 Jan 1 [cited 2018 Jul 7];12(1). Available from: https://www.ajol.info/ index.php/pamj/article/view/81896

9. Gluckman PD, Hanson MA, Cooper C, Thornburg KL. Effect of in utero and early-life conditions on adult health and disease. N Engl J Med. 2008 Jul 3; 359(1):61-73.

10. Laptook AR, Shea TMO, Shankaran S, Bhaskar B. Adverse neurodevelopmental outcomes among extremely Low birth weight infants with a Normal head ultrasound: prevalence and antecedents. Pediatrics. 2005 Mar 1;115(3):673-80.

11. Black SE, Devereux PJ, Salvanes KG. From the cradle to the labor market? The effect of birth weight on adult outcomes. Q J Econ. 2007 Feb 1;122(1): 409-39.

12. Russell RB, Green NS, Steiner CA, Meikle S, Howse JL, Poschman K, et al. Cost of hospitalization for preterm and Low birth weight infants in the United States. Pediatrics. 2007 Jul 1;120(1):e1-9.

13. Gilbert WM, Nesbitt TS, Danielsen B. The cost of prematurity: quantification by gestational age and birth weight. Obstet Gynecol. 2003 Sep 1;102(3): 488-92. 
14. Petrou S. Economic consequences of preterm birth and low birthweight. BJOG Int J Obstet Gynaecol. 2003;1 10(s20):17-23.

15. Elshibly EM, Schmalisch G. The effect of maternal anthropometric characteristics and social factors on gestational age and birth weight in Sudanese newborn infants. BMC Public Health. 2008 Jul 18;8:244.

16. Boney CM, Verma A, Tucker R, Vohr BR. Metabolic syndrome in childhood: association with birth weight, maternal obesity, and Gestational Diabetes Mellitus. Pediatrics. 2005;115(3):e290-6.

17. Neggers Y, Goldenberg RL, Cliver SP, Hoffman HJ, Cutter GR. The relationship between maternal and neonatal anthropometric measurements in term newborns. Obstet Gynecol. 1995 Feb 1;85(2):192-6.

18. Millennium Development Goals [Internet]. [cited 2018 Jul 10]. Available from: http://et.one.un.org/content/unct/ethiopia/en/home/assistanceframework/millennium-development-goals.html

19. Tarekegn SM, Lieberman LS, Giedraitis V. Determinants of maternal health service utilization in Ethiopia: analysis of the 2011 Ethiopian demographic and health survey. BMC Pregnancy Childbirth. 2014 May 7;14:161.

20. Adane AA, Ayele TA, Ararsa LG, Bitew BD, Zeleke BM. Adverse birth outcomes among deliveries at Gondar University hospital Northwest Ethiopia. BMC Pregnancy Childbirth. 2014 Feb 27;14:90.

21. Teklehaimanot N. Prevalence and factors associated with Low birth weight in Axum and Laelay Maichew districts, North Ethiopia: a comparative crosssectional study. Int J Nutr Food Sci. 2014;3(6):560.

22. Tema T. Prevalence and determinants of low birth weight in Jimma zone Southwest Ethiopia. East Afr Med J. 2006 Jul;83(7):366-71.

23. Assefa N, Berhane Y, Wealth Status WA. Mid upper arm circumference (MUAC) and antenatal care (ANC) are determinants for Low birth weight in Kersa. Ethiopia PLOS ONE. 2012 Jun 29;7(6):e39957.

24. Bharati P, Pal M, Bandyopadhyay M, Bhakta A, Chakraborty S, Bharati P. Prevalence and causes of low birth weight in India. Malays I Nutr. 2011 Dec; 17(3):301-13.

25. Demelash H, Motbainor A, Nigatu D, Gashaw K, Melese A. Risk factors for low birth weight in bale zone hospitals, south-East Ethiopia : a case-control study. BMC Pregnancy Childbirth. 2015 Oct 13;15:264.

26. Kastro S, Demissie T, Yohannes B. Low birth weight among term newborns in Wolaita Sodo town, South Ethiopia: a facility based cross-sectional study. BMC Pregnancy Childbirth. 2018 May 11;18(1):160.

27. Golestan M, Akhavan Karbasi S, Fallah R. Prevalence and risk factors for low birth weight in Yazd. Iran Singapore Med J. 2011 Oct 1;52(10):730-3.

28. Ødegård RA, Vatten LJ, Nilsen ST, Salvesen KÅ, Austgulen R. Preeclampsia and fetal growth. Obstet Gynecol. 2000 Dec 1;96(6):950-5.

29. Siza JE. Risk factors associated with low birth weight of neonates among pregnant women attending a referral hospital in northern Tanzania. Tanzan J Health Res. 2008 Jan 1;10(1):1-8.

30. Xiong X, Demianczuk NN, Buekens P, Saunders LD. Association of preeclampsia with high birth weight for age. Am J Obstet Gynecol. 2000 Jul 1;183(1):148-55

31. Xiong $X$, Demianczuk NN, Saunders LD, Wang F-L, Fraser WD. Impact of preeclampsia and gestational hypertension on birth weight by gestational age. Am J Epidemiol. 2002 Feb 1;155(3):203-9.

32. Brocklehurst $P$, French $R$. The association between maternal HIV infection and perinatal outcome: a systematic review of the literature and metaanalysis. BJOG Int J Obstet Gynaecol 105(8):836-48.

33. de Pee S, Semba RD. Role of nutrition in HIV infection: review of evidence for more effective programming in resource-limited settings, role of nutrition in HIV infection: review of evidence for more effective programming in resource-limited settings. Food Nutr Bull. 2010 Dec 1;31(4 suppl4):S313-44.

34. Markson LE, Turner BJ, Houchens R, Silverman NS, Cosler L, Takyi BK. Association of Maternal HIV infection with Low birth weight. JAIDS. J Acquir Immune Defic Syndr. 1996 Nov 1;13(3):227.

35. Aebi C, Battegay M, Bernasconi E, Semprini AE. The European collaborative study. Combination antiretroviral therapy and duration of pregnancy. AIDS. 2000 Dec 22;14(18):2913-20.

36. Hirve SS, Ganatra BR. DETERMINANTS OF LOW BIRTH WEIGHT: A COMMUNITY BASED PROSPECTIVE COHORT STUDY. :5.

37. Hailu LD, Kebede DL. Determinants of Low birth weight among deliveries at a referral Hospital in Northern Ethiopia. Biomed Res Int. 2018;2018:8169615.

38. Ju AC, Heyman MB, Garber AK, Wojcicki JM. Maternal obesity and risk of preterm birth and Low Birthweight in Hawaii PRAMS, 2000-2011. Matern Child Health J. 2018 Jun 1;22(6):893-902.

Ready to submit your research? Choose BMC and benefit from:

- fast, convenient online submission

- thorough peer review by experienced researchers in your field

- rapid publication on acceptance

- support for research data, including large and complex data types

- gold Open Access which fosters wider collaboration and increased citations

- maximum visibility for your research: over $100 \mathrm{M}$ website views per year

At BMC, research is always in progress.

Learn more biomedcentral.com/submissions 